\title{
Economic Evaluation of New Product Creation and Launching: The Case of Unstable Rowing Simulator
}

\author{
Assoc. Prof. Dr. Ligita Gaspareniene
}

Mykolas Romeris University Email: ligita.vasiliauskiene@ktu.It

Assoc. Prof. Dr. Rita Remeikiene

Mykolas Romeris University

Email: rita.remeikiene@mruni.eu

Doi:10.5901/mjss.2014.v5n27p1741

Abstract

The article aims at the economic evaluation of launching a completely new product - an unstable rowing simulator. The analysis of the scientific literature has revealed that creation and launching of new products consists of 8 stages - from generation of ideas to launching. Since for the economic evaluation of the unstable rowing simulator there were no opportunities to apply the formalized methods, the method of expert evaluation was engaged. The results of the expert evaluation have revealed that the unstable rowing simulator is useful for personal health. It improves balance, coordination and suits fitness clubs. Simulator's market price should fall into the interval from 2001 to 3000 Litas.

Keywords: new product creation and launching, unstable rowing simulator, expert evaluation.

\section{Introduction}

Relevance of the topic. Personal well-being and productivity has become the issue actively discussed in the modern society alongside with the issues of health promotion, treatment and rehabilitation. People who suffer from any kind of pain seek for effective solutions for their problems. The interaction between personal and technical measures as well as the ability to help the organism to maximize the use of physiological powers brings significant benefits while seeking for the best results in sports or fitness. Due to this reason, creation of the equipment and stimulators that can help to exercise qualitatively, solve health problems and keep one fit is relevant responding to the needs of modern society.

The problem. Kotler, Keller (2007), Winer (2012), Pranulis, et. al. (2012), Cooper (1999), Choi, et. al. (2005) and other scientists in their studies confirm that new product creation and launching is a long processconsisting of several stages that have to be covered consistently. What is more, the already-formed consumers' attitude towards particular goods has to be considered, so abundant information dissemination is necessary.

The identified problematical situation enables to define the scientific problem following the questions:

- what new product could be created and when could it be launched?

- what is the need for an unstable rowing simulator?

The object of the research is the process of new product creation and launching.

The aim of the research is to perform the economic evaluation of unstable rowing simulator creation and launching.

The methods of the research include the analysis of the scientific literature and expert evaluation.

\section{Literature Review: The Process of New Product Creation and Launching}

New product creation is one of the ways enabling an enterprise to gain competitive advantage, decrease the threat of new competitors, and increase its market share, sales and profit. New product creation is usually promoted by changing demand and the supply offered by competitors. Consumers often change their attitudes towards products since new ones that better meet their needs are launched. Furthermore, under the conditions of intense competition, companies try to gain competitive advantage against each other, thus, they aim at offering consumers the products with better 
characteristics. As s result, new products that stand out from competitors' products and better meet consumers' needs are created. With reference to Winer (2012), Pranulis, et. al. (2012) identify 8 stages of new product creation (see Fig. 1).
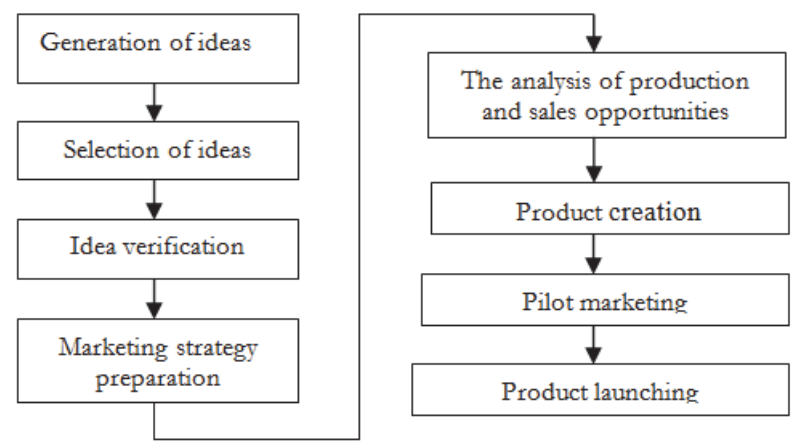

Figure 1. The stages of new product creation (Winer (2012), Pranulis, et. al. (2012))

Pranulis, et. al. (2012) note that new product creation starts from generation of ideas. The ideas can be proposed by consumers, wholesale or retail employees, company staff, independent market researchers or scientists (Pranulis, et. al., 2012). The main source of the ideas for new industrial products is consumers (Kotler, Keller, 2007). Their complaints reveal the directions of product quality and maintenance improvement, and the comprehensive analysis of current trends of consumption enables generation of new ideas. Wholesale or retail employees can generate some ideas as a result of their direct communication with consumers who may make suggestions on how a product should look like so that it could better meet consumers' needs. In the same way, many ideas can be generated by the company's staff. Independent market researchers and scientists perform the studies, the results of which can contribute to the generation of ideas for new product creation as well. New ideas can also rise engaging creative measures such as features listing, link establishment, consideration of the task-related combinations, denial of usual presumptions, studying new contexts or performing mental activities, for instance, following "thoughts scheme" (Kotler, Keller, 2007). O'Shaughnessy (2001) note that in the stage of idea selection, all unsuitable ideas have to be rejected since company's expenses in every further stage of new product creation significantly increase.

The concept of the idea verification includes making a detailed description of the potential product, i.e. establishment of product's potential position in the market, assessment of the benefits the product can bring in comparison with other similar products and the establishment of the areas of product's use. According to O'Shaughnessy (2001), the description of the product should include such points as its functions, operational characteristics, specifications, estimations of possible costs and prices while Kotler, Keller (2007) refer to this stage as "revision of ideas" stating that the description of the product should include the idea, product price, creation time and costs, production costs and profit margin.

Marketing strategy preparation is the next stage to be covered. First of all, marketing segmentation has to be performed; after that target market is selected and the behaviour of the target consumers is researched; brand positioning is established; sales volumes and potential market share are predicted; planned profit from new product sales is estimated. Also, the strategies for all marketing complex elements are substantiated. According to Pranulis, et. al. (2012) different marketing strategy is applicable for each product life cycle stage.

In the next stage, the analysis of production and sales opportunities is performed following the prepared marketing strategy. In this stage, opportunities to sell the product with a profit are researched; for this reason, the sales plan is designed. The predicted sales of the new product depend on how often the product is going to be bought, whether the product is durable or non-durable, whether it is fully consumed or not, bought repeatedly or not. Predicting the volumes of sales, the first sales of the new product have to be considered since they determine whether the consumers will buy the product repeatedly; also, the establishment of new product's life cycle is extremely important[ (Pranulis, et. al., 2012). The curve of sales volumes becomes stable in the course of time and reflects the volumes of repeated sales, but thenthe product is not considered to be new (Kotler, Keller, 2007).

Having estimated the predicted volumes of sales, the costs of production and selling as well as the future profit are estimated. In order to estimate the future profit, first of all, product costs have to be calculated. Costs are referred to as expenses, and can be defined as the resources used seeking for a particular purpose and expressed in monetary units. 
The terms "costs", "expenses", "expenditure" are the synonyms meaning self-costs. According to Puteikiene (2009), production self-costs are the resources expressed in monetary units and used for production making and realization. Thus, self-costs show all the expenses (expenditure) which have formed while making and selling particular products. Then, applying profit turning point and risk analysis, expected profit can be estimated.

The stage of product creation requires extremely much investment since in this stage the first product samples are created. The samples are usually verified by involving potential consumers in the process. Alpha and beta research is performed. Alpha research is verification of the product inside the company with a view to establishing product's operational features in different conditions. The research reveals which features have to be improved. After the improvement, beta research is performed, i.e. the prototype of the product is tested in real conditions. In this stage, the product is tested by potential consumers who afterwards express their opinion. Some kinds of products can be tested only in laboratory conditions, but even then the testing should be as realistic as it is possible (Pranulis, et. al., 2012). With reference to Kotler, Ketller (2007) engagement of the prototype in the process of evaluation is facilitated applying the set of the methods referred to as quality function extraction. Following this method, the features of the product desired by the consumers and revealed during the process of market research are turned into the technical features that can be treated by engineers.

Once the product has been created and branded, andits packaging has been made, the product can be launched. The stage of pilot marketing is aimed at the establishment of consumers and salespeople's attitudes towards the new product, its consumption, first and repeated purchase. In this process, four following variables are significant: the volumes of the pilot marketing, the volumes of the first purchase, recognition and purchase frequency (Kotler, Ketller, 2007). Anyway, companies often refuse this stage since its performance is related with much investment and high risks.

After the careful performance of all the stages described above, the final stage - product launching - can be performed. New product creation and launching is a long process which requires participation of the majority of company's employees and the involvement of the wholesale and retail companies, consumers, independent market researchers and scientists. However, companies often refuse to perform particular stages of the new product creation and launching process such as pilot marketing. Refusing one or another stage, companies risk that their new product will not entrench in the market or will not bring the expected or desired results.

\section{The methodology of the research}

With reference to Bartkus (2013) for the evaluation of new products and goods from the economic point of view, traditional, mathematical, heuristic (psychological), specific (SWOT and FVA) and graphical (diagrams, charts, etc.) methods of economic analysis can be applied.

For the performance of economic evaluation, when the factors do not have any quantitative expressions (as in the case of the researched unstable rowing simulator) and can not be evaluated applying formalized methods, application of the method of expert evaluation is purposeful since the evaluations of carefully selected experts can be considered reliable and representative.

The questionnaire consisting of 20 statements about the unstable rowing simulator was presented to the experts. The statements were divided into four following groups: about the features, demand, price and necessity of the unstable rowing simulator. The experts were asked to evaluate each of the statements in the scale from 1 (completely disagree) to 5 (completely agree). Depending on the strength of the agreement (disagreement), the experts could also select intermediate numerical values 2, 3 or 4 meaning respectively disagree, neither agree nor disagree, agree. The experts had to meet the following requirements: to work in sport or rehabilitation sphere not shorter than 3 years and to be the professionals in their sphere. Six experts, who met all the requirements, were selected and asked to participate in the research.

\section{Economic evaluation of the unstable rowing simulator}

The analysis of the data of the research proposes that the statement confirmed by the majority of the experts was that the simulator improves balance and coordination. Also, most of the experts agreed that the simulator imitates the movements of rowing sport and that it suits fitness clubs. The experts not such much but rather enough agreed with the statements that the simulator trains the deep muscles of the body, it can be used in both stable and unstable positions and it is suitable for rehabilitation (back pain relief).

Most opinions of the experts coincided evaluating the statements of the fourth group, and the experts disagreed with the statement that the price of the simulator could be from 4001 to 5000 Litas or higher. They also disagreed with the 
price from 3001 to 4000 Litas. The price falling in the interval from 2001 to 3000 Litas earned the agreement of the biggest part of the experts.

The evaluations did not coincide for the statement 18 which proposes that the simulator interested the expert. For this statement, the evaluations distributed from 1 to 5 . However, it is important to note that this statement is subjective and asks the personal opinion, the feeling, thus, mismatch of the opinions is justifiable. The results of the research have been presented in Table 1.

Table 1. Numerical characteristics of the expert evaluation forthe unstable rowing simulator (compiled by the authors)

\begin{tabular}{|c|l|c|c|c|c|c|}
\hline No. & \multicolumn{1}{|c|}{$\begin{array}{c}\text { The statements about the unstable rowing } \\
\text { simulator }\end{array}$} & $\begin{array}{c}\text { The number of } \\
\text { the experts }\end{array}$ & $\begin{array}{c}\text { Minimal } \\
\text { evaluation }\end{array}$ & $\begin{array}{c}\text { Maximal } \\
\text { evaluation }\end{array}$ & Average & $\begin{array}{c}\text { Standard } \\
\text { deviation }\end{array}$ \\
\hline k01 & Trains deep muscles & 6 & 3 & 4 & 3.67 & 0.516 \\
\hline k02 & Does not damage the posture & 6 & 2 & 4 & 3.33 & 1.033 \\
\hline k03 & Helps for back pain relief & 6 & 2 & 4 & 3.00 & 0.894 \\
\hline k04 & Improves balance, coordination & 6 & 4 & 4 & 4.00 & 0.000 \\
\hline k05 & Imitates rowing movements & 6 & 3 & 5 & 3.83 & 0.753 \\
\hline k06 & Can be used as both stable and unstable & 6 & 3 & 5 & 3.67 & 0.816 \\
\hline k07 & Necessary for Lithuanian market & 6 & 3 & 4 & 3.50 & 0.548 \\
\hline k08 & It will earn interest & 6 & 2 & 4 & 3.33 & 0.816 \\
\hline k09 & It is suitable for rehabilitation (back pain relief) & 6 & 2 & 5 & 3.67 & 1.033 \\
\hline k10 & Suits fitness clubs & 6 & 3 & 4 & 3.83 & 0.408 \\
\hline k11 & Suits professional rowers outside the season time & 6 & 1 & 4 & 3.00 & 1.095 \\
\hline k12 & Suits home customers & 6 & 2 & 4 & 3.17 & 0.753 \\
\hline k13 & It should be priced under 2000Lt. & 6 & 1 & 4 & 3.00 & 1.095 \\
\hline k14 & It should be priced from 2100 to 3000 Lt & 6 & 2 & 4 & 3.33 & 1.033 \\
\hline k15 & It should be priced from 3001 to 4000 Lt & 6 & 1 & 4 & 1.67 & 1.211 \\
\hline k16 & It should be priced from 4001 to 5000 Lt & 6 & 1 & 2 & 1.17 & 0.408 \\
\hline k17 & It should be priced over 5001 Lt & 6 & 1 & 2 & 1.17 & 0.408 \\
\hline k18 & Simulator interested me & 6 & 1 & 5 & 3.50 & 1.378 \\
\hline k19 & I would recommend it & 6 & 2 & 4 & 3.17 & 0.753 \\
\hline k20 & I would consider purchasing it & 6 & 1 & 4 & 3.33 & 1.211 \\
\hline
\end{tabular}

Summarizing the compatibility of the expert evaluations, it can be concluded that the experts agree that the unstable rowing simulator improves balance, coordination, suits fitness clubs and should be priced from 2001 to 3000 Litas.

\section{Conclusions}

The theoretical analysis has revealed that new product creation and launching is a long process; thus, companies should carefully perform all eight stages of the process: generation and selection of ideas, idea verification, marketing strategy preparation (branding, pricing, marketing channel and promotion strategy selection), the analysis of production and sales opportunities, product creation, pilot marketing and product launching. Before launching a new product, it is purposeful to carry out the economic evaluation to assess whether product launching is beneficial or not.

The expert evaluation has revealed that the opinions of the experts coincided, $W=0.407$. The experts agree that the unstable rowing simulator improves balance, coordination, suits fitness clubs and should be priced from 2001 to 3000 Litas.

\section{References}

Bartkus E. V. (2013). Inovaciju valdymas ir ekonominis vertinimas. Klaipèda.

Choi, W., Powell, N. B., Cassill, N. (2005). Product Development and its Application in Textiles. Journal of Textile and Apparel, Technology and Management. Vol. 4, Issue 4, 1-28.

Cooper, R. G. (1999). From Experience: The Invisible Success Factors in Product Innovation. Journal of Product Innovation Management 16, 115-133.

Kotler P., Keller K.L. (2007). Marketingo valdymo pagrindai. Klaipėda: Logitema.

O'Shaughnessy, D. (2001). Competitive marketing. London: McGrew Hill.

Pranulis, V., Pajuodis, A., Urbonavičius, S., Virvilaité, R., (2012). Marketingas. ISBN 978-9955-883-21-0. 
Puteikienè, R. (2009). Verslo ekonomika. Vilnius: Vilniaus Kolegija.

Winer, R. S. (2012). Marketing Management. Pearson education, Inc., Upper Saddle River, New Jersey, 07458. 